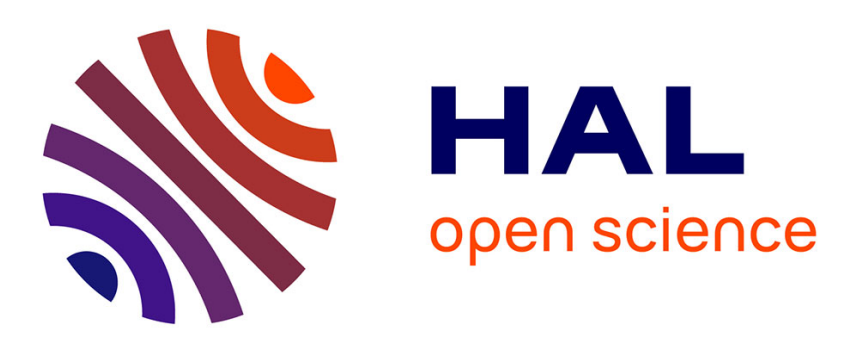

\title{
Decoding Relationships of Success Factors for Lean Information Technology Outsourcing
}

\author{
Vincent Blijleven, Afshin Mehrsai
}

\section{To cite this version:}

Vincent Blijleven, Afshin Mehrsai. Decoding Relationships of Success Factors for Lean Information Technology Outsourcing. IFIP International Conference on Advances in Production Management Systems (APMS), Sep 2015, Tokyo, Japan. pp.332-339, 10.1007/978-3-319-22759-7_39 . hal-01431113

\section{HAL Id: hal-01431113 \\ https://hal.inria.fr/hal-01431113}

Submitted on 10 Jan 2017

HAL is a multi-disciplinary open access archive for the deposit and dissemination of scientific research documents, whether they are published or not. The documents may come from teaching and research institutions in France or abroad, or from public or private research centers.
L'archive ouverte pluridisciplinaire HAL, est destinée au dépôt et à la diffusion de documents scientifiques de niveau recherche, publiés ou non, émanant des établissements d'enseignement et de recherche français ou étrangers, des laboratoires publics ou privés. 


\title{
Decoding Relationships of Success Factors for Lean Information Technology Outsourcing
}

\author{
Vincent Blijleven and Afshin Mehrsai \\ Center for Marketing and Supply Chain Management \\ Nyenrode Business Universiteit \\ Straatweg 25, 3621 BG Breukelen, the Netherlands \\ \{v.blijleven, a.mehrsai\}@nyenrode.nl
}

\begin{abstract}
Managing the continuous growth of modern-day IT developments and its transformation consequences in manufacturing and service organizations is arduous. It burdens organizations and supply chain management. For decades, supply chain managers have outsourced their non-specialized IT activities to third-parties. Competition compels organizations to look for ever more effective services from their suppliers. Solely outsourcing IT activities is no longer sufficient. Monitoring and optimization has become decisive. Lean, a successful philosophy to pursue continuous improvement, is extending its contributions from manufacturing and services to IT processes. This paper explores the success factors for the implementation of Lean in IT outsourcing relationships. It aids managers in designing a dashboard to optimize and monitor the implementation of Lean in IT outsourcing relationships. The causalrelationships among success factors in the context of a system, based on multiple case studies, is decoded through a causal-loop diagram and sensitivity analysis inspired by the system dynamics methodology.
\end{abstract}

Keywords: critical success factors, lean, information technology outsourcing, simulation, system dynamics

\section{Introduction}

Contributions of recent information technology (IT) developments influence all organizational areas and challenge contemporary supply chain manage-ment (SCM) practices 2. Today, coordination and integration of supply chain activities strongly depend on the performance of modern contributions of IT throughout the value chain [12. Outsourcing IT value chain activities can be a driver of flexibility, agility and leanness of supply chains 13 . For this reason, for decades, managers have made the strategic decision to delegate their non-specialized operations, including IT activities to external professional suppliers, termed IT outsourcing [10. Among those delegated activities are IT operations, support, development and maintenance. Although the practices of IT outsourcing have been thoroughly researched over the last two decades, many IT outsourcing clients remain dissatisfied 7. This is demonstrated by low satisfaction rates, 
a high number of backsourcing decisions, and vendor switching [19. The main problems clients experience are degradations of service over time, lacking vendor commitment, delayed deliveries or slow implementations [7.

Solely outsourcing IT activities is no longer sufficient. Monitoring and optimization of outsourcing relationships has become decisive to succeed in the market [5]. In doing so, Lean, as a successful philosophy to pursue continuous improvement, is extending its contributions from manufacturing and services to IT processes. When speaking of Lean, we refer to Womack and Jones (2003) 20. who describe Lean as a five-step management philosophy that, in essence, allows (1) organizations to specify value, i.e., what the customer is willing to pay for, (2) to identify all value-creating activities while eliminating those that do not, (3) to align these activities to achieve flow, (4) to let customers pull the value, and (5) to achieve and sustain perfection. This process is often termed Lean transformation 4. From an IT outsourcing perspective, the focus of Lean lies on aiming to fulfill the desire of clients by suppliers. This is realized by precisely defining the needs of clients and optimizing value-adding activities through continuous improvement, while using the least amount of resources necessary. Reported motivations to implement Lean in IT outsourcing are shortening application maintenance times, achieving higher software release frequencies, stimulating co-innovation and learning, and reducing software development costs 3 .

To realize successful continuous improvement in IT outsourcing relationships through Lean, managers should first know what factors matter in this context. Through multiple case studies conducted, critical success factors (CSFs) [15] have been identified that indicate the key areas managers should focus on, to successfully implement Lean in IT outsourcing relationships [3]. However, understanding how these factors directly and indirectly influence each other, including the overall outsourcing relationship, is not straightforward. In order to address this issue, system dynamics (SD) as a methodology is deemed suitable for decoding the intricate relationships among CSFs [1]. In this paper, the causalrelationships among identified CSFs is explored by utilizing a systems thinking approach and involves the creation of a causal-loop diagram (CLD) and performing subsequent simulations. The results of so-called sensitivity analysis simulation highlight the importance and influence of several CSFs and related factors on the overall IT outsourcing relationship performance.

The remainder of this paper continues with an overview of the identified CSFs in Section 2. Section 3 presents a description of the research approach, followed by Section 4 providing an elaboration upon the contribution of SD to decode the CSFs. Section 5 presents an analysis of the system model addressing several CSFs. Section 6 then concludes this paper by pointing out the contribution and limitation of this study, and provides directions for future research.

\section{Critical Success Factors}

According to Rockart (1979, p. 85) 14, CSFs are "the limited number of areas in which results, if they are satisfactory, will ensure successful competitive 
performance for the organization". CFSs have a prominent place in Information Systems (IS) research and have been one of the earliest and most actively researched topics in the IS field [11. For instance, it has been formerly used to analyze the implementation of IT outsourcing practices 8 .

This paper explores the 16 CSFs and related factors derived from 36 interviews conducted during six case studies in different sectors by [3] for the implementation of Lean in IT outsourcing relationships (see Table 1 for an overview of the cases studied). This paper goes one step further by extending the identified success factors into a richer framework that describes their causal-interrelationships and decodes them accordingly. The 16 CSFs have been included in the CLD (see Figure 22). In order to see the whole picture of factors influencing the success of Lean implementation and their underlying relationships, however, other factors beside the CSFs that influence the success of Lean implementation in the IT outsourcing relationship, but did not fit the criteria to carry the label 'critical' 15, have also been included in the CLD. To distinguish between critical and non-critical factors, the CSFs have been printed in bold whereas non-critical factors are printed in plain text.

Table 1. Overview of key characteristics of the cases studied.

\begin{tabular}{|l|l|l|l|l|l|}
\hline Client & Industry & Supplier & Content & Size & Age \\
\hline Client A & Insurance & Supplier E & Development & 100 & 2 \\
\hline Client A & Insurance & Supplier F & Maintenance & 50 & 4 \\
\hline Client A & Insurance & Supplier G & Development & 3 & 1.5 \\
\hline Client B & Telecoms & Supplier H & $\begin{array}{l}\text { Maintenance \& } \\
\text { Development }\end{array}$ & 15 & 2.5 \\
\hline Client C & Government & Supplier I & Development & 5 & 1.5 \\
\hline Client D & Food & Supplier J & $\begin{array}{l}\text { Maintenance \& } \\
\text { Development }\end{array}$ & 9 & 5 \\
\hline
\end{tabular}

\section{$3 \quad$ Research Method}

An overview of all the consecutive research steps taken during this project, including their corresponding deliverables, is shown by means of a processdeliverable diagram (PDD) in Figure 1. PDDs use UML and consist of two different, yet connected parts [18. On the lefthand side, the activities conducted during this research project are modeled. The deliverables as a result of these activities, connected with dashed lines, are modeled on the right-hand side of the diagram.

For the purpose of analyzing the 16 CSFs and related factors and to uncover the relationships among them, a CLD was created with a software application named Vensim PLE1. The CSFs were first added in Vensim as separate variables

\footnotetext{
${ }^{1}$ http://www.vensim.com/
} 
that form the basis of the CLD (see Figure 2). Afterwards, positive and negative relationships among these variables were identified and added to the diagram and reviewed by experts. Subsequently, based on the CLD, sensitivity analysis simulations could be designed and run to examine policies of managers.

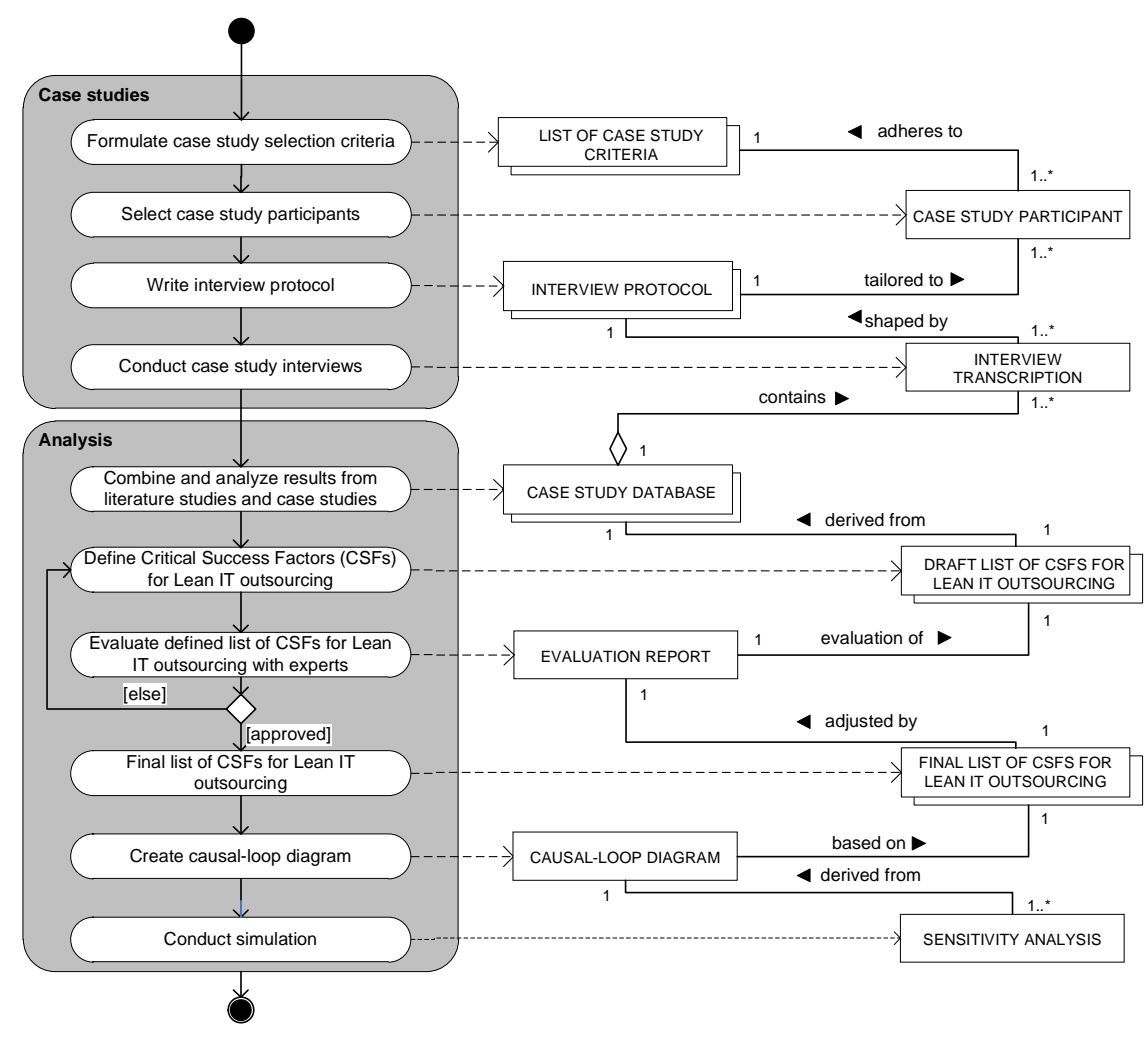

Fig. 1. Illustration of the research steps taken.

\section{Contribution of System Dynamics}

SD is a business process modeling methodology by making a use of systems thinking for getting a systematic perspective to complex interrelated problems with causalities [17. This methodology was depicted by Jay Forrester at MIT in the 1960s. Systems thinking provides a problem solving approach by considering each problem as a part of an inclusive system rather than reacting to an isolated section [17. In short, SD illustrates the causal relationships between the factors in the context of a system, i.e., direct and indirect relationships can be found by means of a CLD. Basically, interrelated causes and effects of elements in a 
system, representing mental models, lead to a positive or negative CLD; which aim at reinforcing or counteracting change in the system, respectively [17.

The major contribution of SD and its associate software ("Vensim") to the current study is manifold. First, SD can be used to define a thorough graphical topology of complex causal relationships among factors in Lean IT outsourcing relationships between clients and suppliers. The initial privilege of configuring the CLD of a system is the detection of direct and indirect relationships between its elements, which are difficult to recognize in a tabular form. Second, by means of the CLD, the borders of the entire problem can be distinguished. This provides a systematic perspective with defined exogenous/indigenous elements of the case studied. Third, after modeling the CLD of factors, this can assist the interested parties with understanding negative and positive feedback loops by adding polarities, and reveals the nonlinear structure of the system. The modeling position of the factors, turned into variables now, according to their supportive, contributive, and principal roles, can be classified into auxiliary, flow, and stock, respectively. Fourth, the next step is setting up a simulation model that describes the behavior of the system in a given period of time. On this basis, Figure 2 has been developed from the case studies. The entire content of the CLD as shown in Figure 2 is too much to discuss. Instead, it is limited to a selection of these factors. In the next section, it can be seen that four variables play a central role in the diagram, being the success of Lean implementation, trust, culture of continuous improvement, and close cooperation to identify and eliminate waste.

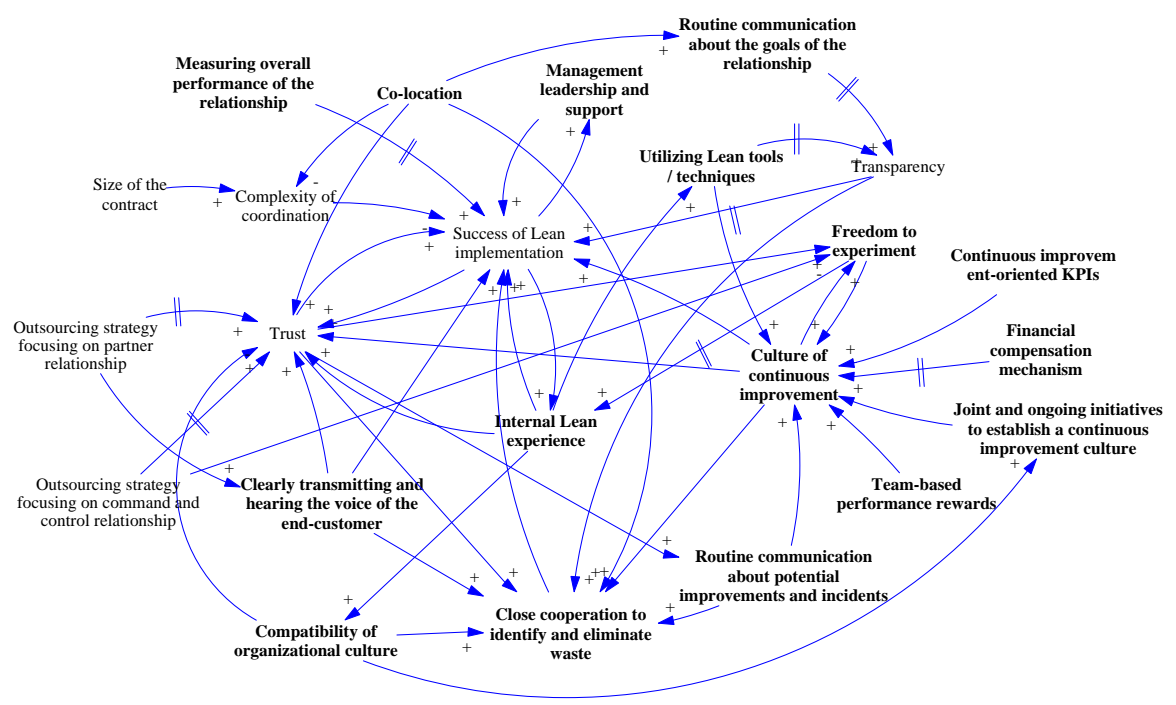

Fig. 2. Causal-loop diagram showing the causal interrelationships among the identified success factors for Lean IT Outsourcing. 


\section{Sensitivity Analysis}

Basically, three alternative scenarios, being Base 1, Base 2 and Base 3, are assumed to experiment with the performance of the model. In order to reflect the role of time lag (delay) in the dynamic behavior of the system, for each stock (control factor) an adjustment time (AT) is devised. Among them "Lean transformation AT" is chosen to vary (see the exemplary stock and flow diagram in Figure 3). Next, in Base 4 to check the importance of voice-of-customer (VoC), the variable "Rate of transmitting and hearing the voice of end customer" undertakes random numbers through the simulation horizon, following the normal distribution, see Table 2. These alternative scenarios result in the sensitivity analysis of the entire model.

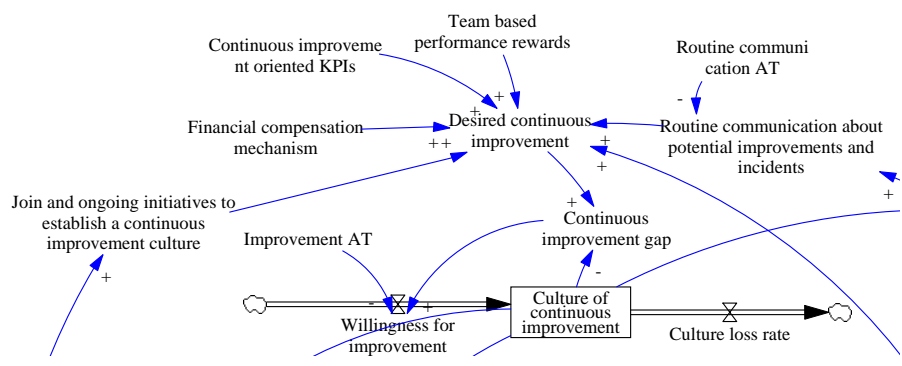

Fig. 3. Exemplary stock and flow diagram.

Table 2. Sensitivity analysis scenarios.

\begin{tabular}{|l|c|c|c|c|}
\hline \multirow{2}{*}{ Variable } & \multicolumn{4}{|c|}{ Scenario } \\
\cline { 2 - 5 } & Base 1 & Base 2 & Base 3 & Base 4 \\
\hline Lean Transformation AT & 1 week & 10 weeks & 5 weeks & 5 weeks \\
\hline Rate of transmitting and hearing the voice of end-customer & Constant $=0.5$ & Constant $=0.5$ & Constant $=0.5$ & $N^{(}(\mu=0.5, \sigma=0.2)$ \\
\hline
\end{tabular}

As it is seen in Base 1, Base 2 and Base 3, the role of AT in transformation is crucial. By increasing the delay in transformation, all other key factors get negatively influenced as well, as their growth curves level off (see Figure 4). Besides, by looking at Base 4, it can be observed that oscillation in meeting the exact customer need (VoC) leads to fluctuations in related direct and indirect factors. This phenomenon is not desired neither in supply chain management [9] nor in any Lean initiative [16]. This gives rise to either unsatisfied customers or excessive lag hampering the success of operations. The responsibility of Lean managers and leadership is to avoid such disruptions as much as possible [6]. 


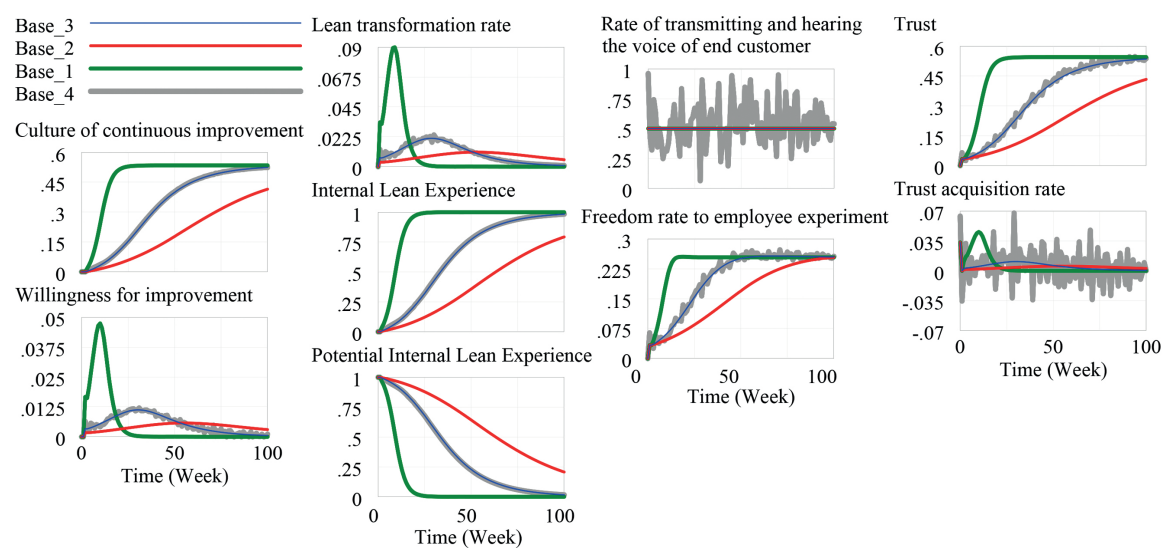

Fig. 4. Sensitivity analysis diagrams.

\section{Conclusion}

In this paper, the emerging management challenge of dealing with the growing demand of IT in various business sectors is discussed. As aforementioned, today, IT is the backbone of any business to facilitate collaborating, networking, providing, and delivering products / services to customers. Therefore, outsourcing these operations, while optimizing the implementation of the processes, reduces a major burden on businesses. In doing so, recently, Lean management with its prominent methods and tools are combined with IT processes for the sake of optimization. 16 CSFs have been identified in prior literature based on case study research. To show how these CSFs affect a successful and efficient implementation of Lean IT outsourcing, the SD methodology is applied to decode the complex causalities between these factors and their effect on outsourcing success. The CLD defined the associations and unfolded the complex feedback loops among the elements in the management system. Moreover, a simulation model is developed to be used for policy experiments and sensitivity analysis, of which the results were presented. It could be seen that delay in any adjustment and transformation is crucial to the duration it takes to achieve success. Furthermore, the importance of $\mathrm{VoC}$ is illustrated by demonstrating its fluctuations in other CSFs. In summary, this study shed light upon the comprehension of the role of CSFs in the context of a management system, and elaborated upon the monitoring and tracking capability of managers in their IT outsourcing decisions. Nonetheless, development of an authentic SD simulation model depends on several aspects, including availability of historical data, configured reference modes, and precision of mathematical equations used in the model. SD models are therefore by themselves always subject to improvement and the same holds for the model in this paper. Future research will improve and adjust the equations and expand the CLD of CSFs to incorporate more details concerning outsourcing, IT, and Lean. 


\section{References}

1. Akkermans, H., van Helden, K.: Vicious and virtuous cycles in erp implementation: a case study of interrelations between critical success factors. European journal of information systems 11(1), 35-46 (2002)

2. Bhakoo, V., Singh, P., Chia, A.: Supply chain structures shaping portfolio of technologies: exploring the impact of integration through the dual arcs framework. International Journal of Physical Distribution \& Logistics Management 45(4), 376 399 (2015)

3. Blijleven, V., Gong, Y.: Motivations and critical success factors for lean it outsourcing. Submitted. (2015)

4. Cil, I., Turkan, Y.: An anp-based assessment model for lean enterprise transformation. The International Journal of Advanced Manufacturing Technology 64, 1113-1130 (2013)

5. Elitzur, R., Gavious, A., Wensley, A.K.: Information systems outsourcing projects as a double moral hazard problem. Omega 40(3), 379-389 (2012)

6. Found, P., Harrison, R.: Understanding the lean voice of the customer. International Journal of Lean Six Sigma 3(3), 251-267 (2012)

7. Gorla, N., Somers, T.M.: The impact of it outsourcing on information systems success. Information \& Management 51(3), 320-335 (2014)

8. Gottschalk, P., Solli-Sæther, H.: Critical success factors from it outsourcing theories: an empirical study. Industrial Management \& Data Systems 105(6), 685-702 (2005)

9. Gupta, A., Maranas, C.D.: Managing demand uncertainty in supply chain planning. Computers \& Chemical Engineering 27(8), 1219-1227 (2003)

10. Lacity, M.C., Hirschheim, R.A.: Information Systems Outsourcing; Myths, Metaphors, and Realities. John Wiley \& Sons, Inc. (1993)

11. Lu, X.H., Huang, L.H., Heng, M.S.: Critical success factors of inter-organizational information systemsa case study of cisco and xiao tong in china. Information \& Management 43(3), 395-408 (2006)

12. Mehrsai, A., Karimi, H.R., Thoben, K.D.: Integration of supply networks for customization with modularity in cloud and make-to-upgrade strategy. Systems Science \& Control Engineering: An Open Access Journal 1(1), 28-42 (2013)

13. Mohammed, I.R., Shankar, R., Banwet, D.: Creating flex-lean-agile value chain by outsourcing: An ism-based interventional roadmap. Business Process Management Journal 14(3), 338-389 (2008)

14. Rockart, J.: Chief executives define their own data needs. Harvard Business Review 57(2), 81-93 (1979)

15. Rockart, J., Crescenzi, A.: Engaging top management in information technology. Sloan Management Review 25, 4 (1984)

16. Salah, S., Rahim, A., Carretero, J.A.: Implementation of lean six sigma (lss) in supply chain management $(\mathrm{scm})$ : an integrated management philosophy. International Journal of Transitions and Innovation Systems 1(2), 138-162 (2011)

17. Sterman, J.D.: Business dynamics: systems thinking and modeling for a complex world, vol. 19. Irwin/McGraw-Hill Boston (2000)

18. van de Weerd, I., Brinkkemper, S.: Meta-modeling for situational analysis and design methods. IGI Global (2008)

19. Whitten, D., Leidner, D.: Bringing it back: An analysis of the decision to backsource or switch vendors. Decision Sciences 37(4), 605-621 (2006)

20. Womack, J., Jones, D.: Lean Thinking: Banish Waste and Create Wealth in Your Corporation, Revised and Updated. Productivity Press (2003) 